\title{
Perspectivas da mobilidade urbana sustentável em Campo Grande-MS
}

\section{Perspectives of sustainable urban mobility in Campo Grande-MS}

Perspectivas de la movilidad urbana sostenible en Campo Grande-MS

Renato Saravy Diacópulos Mestrando em Engenharia Urbana, UFSCar, Brasil. renatosaravy@gmail.com

\section{Rochele Amorim Ribeiro}

Professora Doutora, UFSCar, Brasil. rochele@ufscar.br

Luciana Márcia Gonçalves

Professora Doutora, UFSCar, Brasil. lucianamg@ufscar.br 


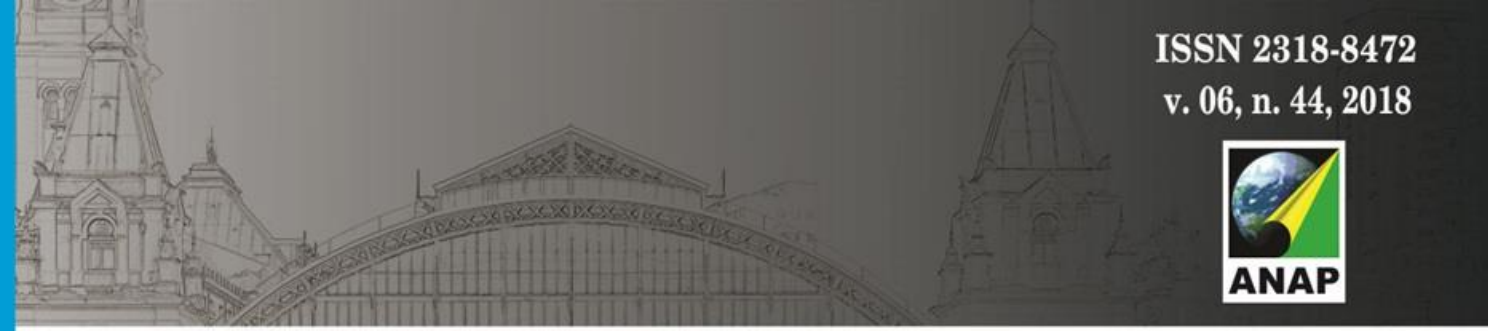

Gerenciamento de Cidades

National Journal of Cities Management

RESUMO

O presente trabalho procurou discutir as novas propostas e as perspectivas da mobilidade urbana sustentável em Campo Grande-MS. Com base em materiais bibliográficos, como o plano diretor e relatórios de projetos feitos na área de estudo, foi feito o levantamento do processo de ocupação urbana, da evolução populacional da cidade, e do sistema de mobilidade urbana existente da cidade. A análise indica que a cidade atravessa por um momento propicio para adoções de propostas de boas práticas para integração de modais. É possível verificar e concluir que Campo Grande possui uma forte tendência para uso das bicicletas na área central estimulando o transporte ativo por meio da inserção de equipamentos públicos e incentivos para o uso da bicicleta como maior segurança viária.

PALAVRAS-CHAVE: Mobilidade Urbana, integração modal, transporte público, bicicletas.

\section{ABSTRACT}

This work sought to discuss the new proposals and the perspectives of sustainable urban mobility in Campo GrandeMS. Based on bibliographic materials, such as the city plan and project reports made in the study area, a survey was made of the urban occupation process, the population evolution of the city, and the city urban mobility system. The analysis indicates that the city crosses for a moment propitious for adoptions of proposals of good practices for the integration of modals. It is possible to verify and conclude that Campo Grande has a strong tendency to use bicycles in the central area by stimulating active transportation through the insertion of public equipment and incentives to use the bicycle as a road safety.

KEYWORDS: Urban Mobility, modal integration, public transportation, bicycles.

\section{RESUMEN}

El presente trabajo trató de discutir las nuevas propuestas y las perspectivas de la movilidad urbana sostenible en Campo Grande-MS. Con base en materiales bibliográficos, como el plan director e informes de proyectos hechos en el área de estudio, se hizo el levantamiento del proceso de ocupación urbana, de la evolución poblacional de la ciudad, y del sistema de movilidad urbana existente de la ciudad. El análisis indica que la ciudad atraviesa por un momento propicio para adoptar propuestas de buenas prácticas para integración de modales. Es posible verificar y concluir que Campo Grande posee una fuerte tendencia para el uso de las bicicletas en el área central estimulando el transporte activo por medio de la inserción de equipamientos públicos e incentivos para el uso de la bicicleta como mayor seguridad vial.

PALABRAS CLAVE: Movilidad Urbana, integración modal, transporte público, bicicletas. 


\section{INTRODUÇÃO}

Mobilidade urbana sustentável é um conceito que se estende muito além dos meios de transportes não poluentes ou menor gasto energético. No contexto atual, abrange a necessidade econômica humana, proteção do meio natural e justiça social. No tocante a sustentabilidade econômica dos sistemas de transporte, podemos citar: a cobertura dos custos; o balanceamento entre oferta e demanda, o investimento na expansão da rede permanentes, os investimentos na melhoria dos serviços permanentes e os modelos de financiamento e remuneração viáveis. Quanto a sustentabilidade ambiental dos sistemas de transporte, pode ser considerado o uso de tecnologias mais limpas do ponto de vista ambiental (emissões e ruídos), de veículos e infraestrutura adequados em áreas de preservação histórica ou ambiental, a baixa intrusão visual e o planejamento urbano e de transporte integrados. Por fim, quanto à sustentabilidade social, pode ser considerada as ações que promovam a tarifa inclusiva, a inclusão social, o atendimento às áreas mais carentes com custo compatível à renda desses usuários, a equidade no uso do espaço urbano, a progressividade no financiamento e regressividade na concessão dos benefícios sociais e a acessibilidade universal ao transporte público (IPEA, 2016).

Cidades de estrutura mais complexa também requerem deslocamentos mais complexos e exigem um sistema de mobilidade urbana que conecte os vários modais de transporte, para tornar os deslocamentos ainda mais ágeis e flexíveis (NTU, 2012). Nesse sentido, os sistemas integrados de transporte podem possibilitar as cidades uma maior conectividade, pois quando analisado individualmente, cada um deles possuem um limitante de oferta do serviço. Quando pensamos no ideal da integração, porta-porta, o uso da bicicleta se mostra mais eficiente, levando em conta seu tamanho, espaço de estacionamento e fluxo rápido em curtas e médias distâncias (SAGARIS; ARORA, 2016).

Desta forma, com o objetivo de promover a sustentabilidade nos sistemas de mobilidade, considerando a complexidade urbana, os governos municipais vêm desnvolvendo planos municipais de mobilidade urbana (PlanMob). A elaboração do PlanMob é regido pelo Caderno de Referência (Ministério das Cidades, 2015), que é um instrumento de orientação aos municípios brasileiros que pretendem e devem elaborar seus planos diretores, plano de mobilidade urbana e outras políticas públicas. Nele estão contidas algumas boas práticas para integração eficiente entre as ciclovias e outros modais, tais como, melhoria nos equipamentos públicos (estacionamento), segurança do usuário (redução da velocidade nas vias). O caderno ainda faz um detalhamento da Lei n. 12.587/2012 (BRASIL, 2012), que estabelece a Política Nacional de Mobilidade Urbana para municípios acima de 20 mil habitantes. A citada Lei estabelecia prazo de três anos, vencido em 2015 para os municípios com mais de 20 mil 
habitantes elaborarem seus Planos de Mobilidade Urbana. Projeto de lei da Câmara (PLC 22/2016) e aprovada no mesmo ano, tratou de elevar esse prazo de três para seis anos contado também a partir de 2012 para as prefeituras cumprirem com essa atribuição (BRASIL, 2016).

Atualmente Campo Grande está passando por revisão do seu Plano Diretor, nele está incluso o Plano Diretor de Transporte e Mobilidade Urbana (CAMPOGRANDENEWS, 2018). Nessa revisão é possível constatar a preocupação com instalações de mais ciclovias na cidade, a fim de estimular o usuário cotidiano, pois a cidade apresenta condições favoráveis para utilização desse modo de transporte não motorizado (LOGITRANS, 2009).

O IBGE (2017) em sua última publicação sobre estimativa populacional verificou que Campo Grande-MS em 2017 possuía 874.210 mil habitantes, classificando-a como cidade grande. Tendo esse rápido crescimento e uma preocupação com o ordenamento da cidade, como, transporte e mobilidade urbana e ocupação e uso do solo, no ano de 2009, no qual inclui na revisão do Plano Diretor, itens relacionados a mobilidade urbana, tal como, expansão da rede cicloviária e nova hierarquia das vias urbanas.

Para a elaboração de Plano de Mobilidade Urbana, é necessário saber como previamente se deu a evolução viária e cicloviária do município. Com esse objetivo, foi feito o levantamento de como Campo Grande está adotando boas práticas relacionadas ao transporte cicloviário, integração entre bicicleta e outros modos de transporte, utilizando o Plano Diretor e o Plano de Transporte e Mobilidade Urbana como bases bibliográficas e projetos elaborados que trazem práticas de mobilidade urbana sustentável.

Nas próximas seções do trabalho, é apresentado como ocorreu a forma de ocupação espacial e a distribuição populacional na cidade, resultando na atual malha viária da cidade e suas necessidades de adaptação aos novos modos de transporte. Por fim, é destacado possíveis estratégias futuras a serem adotadas pela cidade para uma mobilidade urbana mais sustentável.

\section{EVOLUÇÃO URBANA EM CAMPO GRANDE}

A capital de Mato Grosso do Sul, foi uma das cidades brasileiras em que o crescimento se mostrou muito acelerado entre 1960 e 1990, quando sua população chegou a dobrar a cada década (LE BOURLEGAT, 2000). Mesmo após o levantamento feito pela autora até a década de 1990, a cidade continua sua expansão, porém menos acelerada nas décadas de 2000 e 2010 (Mapa 1) 


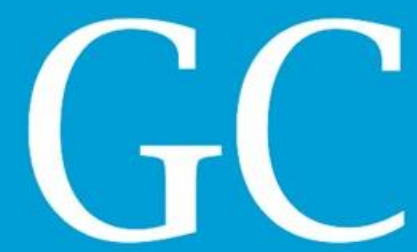

Revista Nacional de

Figura 1 - Mapa da evolução da ocupação urbana em Campo Grande - MS

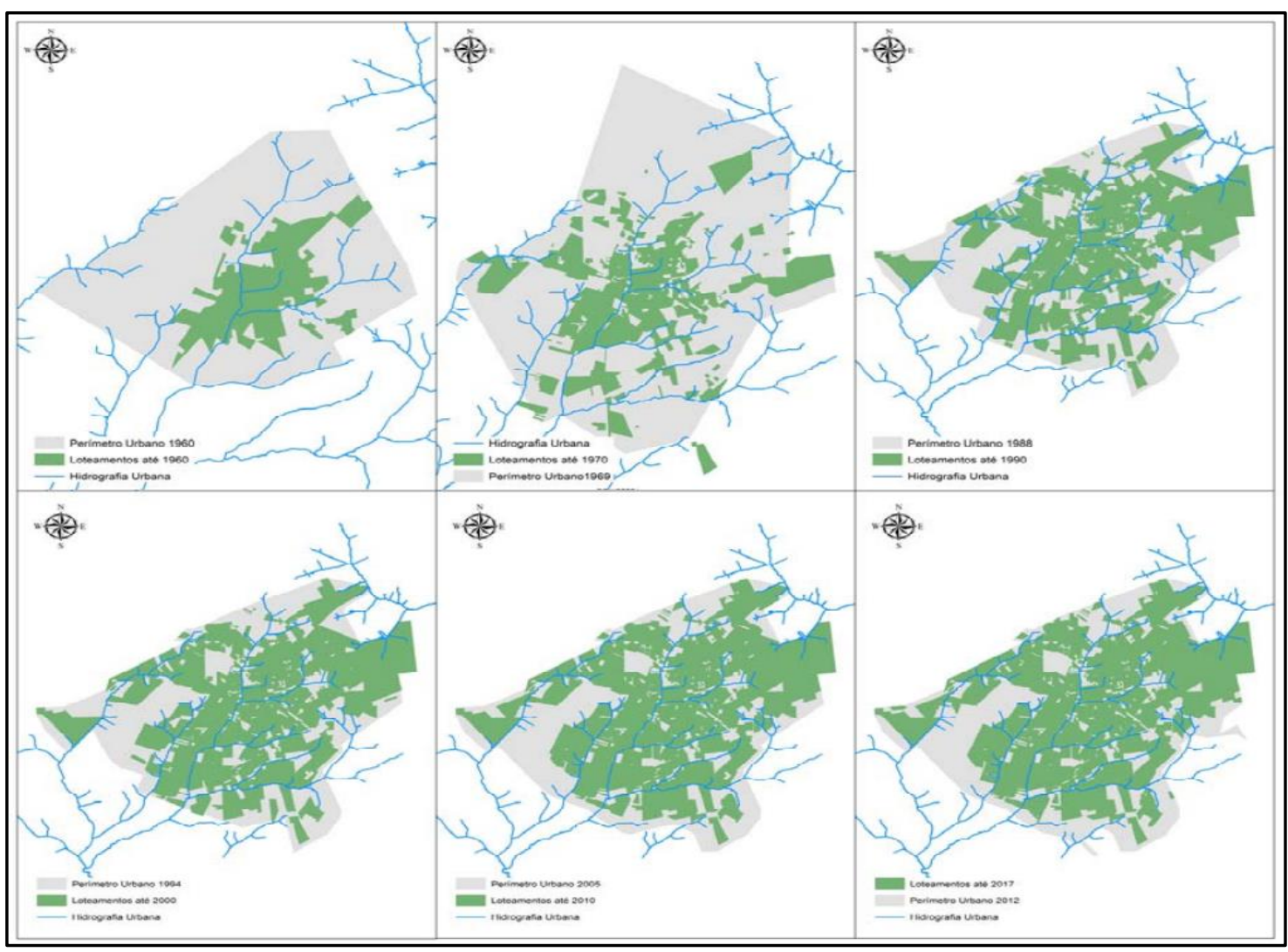

Fonte: PLANURB, 2018

Com o crescimento urbano, e o encontro de modais rodoviários e ferroviários, a cidade contribuiu para dotá-la de uma estrutura centralizada, enquanto a expansão urbana passou a ocorrer ao longo de grandes eixos viários. Estes partiam do grande nó central de comércio e serviços em direção às saídas da cidade. Essa dinâmica de urbanização, segundo a autora, propiciou um formato radial de expansão e favoreceu a permanência de vazios nos ângulos internos formados por esses grandes corredores de circulação, especialmente em situações mais periféricas (LE BOURLEGAT, 2000).

No final dos anos 80 Campo Grande apresentava a classificação demográfica de cidade média, pois, impulsionada pelo incentivo da modernização agrícola brasileira, assim como toda Região Centro-Oeste nos anos 70 e 80, foram oferecidas condições ideais para expansão do agronegócio, modificando a dinâmica populacional da Região e país (CUNHA, 2006). 
$\mathrm{Na}$ década de 80 a cidade conheceu maior adensamento nos interstícios vazios, especialmente após 1988, quando por meio de Lei Municipal no 2.567, de 8 de dezembro de 1988 (CAMPO GRANDE, 1988), sobre Orçamento do Uso e Ocupação do Solo, estabeleceu-se um perímetro urbano, que dificultava o novo espraiamento da malha urbana. No início dos anos 90 foi construído o grande macro anel rodoviário que freou ainda mais uma possível expansão urbana.

Campo Grande é hoje um município urbano, com cerca de $99 \%$ da sua população ( 776.242 habitantes em 2010) residem na cidade enquanto pouco mais de 10 mil pessoas residem na área rural. No ano de 2017 o município tinha uma população estimada em 874.210 habitantes (IBGE, 2017).

\section{CAMPO GRANDE E SEU SISTEMA DE TRANSPORTE PÚBLICO}

O primeiro grande planejamento sobre transporte coletivo de ônibus em Campo Grande ocorreu em 1991, mediante implantação de terminais de transbordo com linhas especiais. 0 objetivo foi integrar a rede de transporte por meio de terminais de integração, para permitir o transbordo de passageiros entre as diversas modalidades de linhas do sistema. Naqueles bairros mais periféricos não contemplados pela integração foram mantidas as linhas convencionais nessa fase inicial. A partir de 1998, deu-se início às interligações dos terminais instalados com as linhas convencionais dos bairros (OLIVEIRA, 2003).

Nesse sistema integrado do transporte coletivo de ônibus, as "linhas tronco-diametrais" foram implantadas nos grandes corredores de circulação. $\mathrm{O}$ objetivo nesse processo de estruturação do transporte coletivo passageiros foi inserir os terminais de transbordo nas extremidades desses grandes corredores. Estes terminais contribuíam para conectar outros corredores adjacentes, que foram considerados "linhas tronco-interbairros". Essa estrutura integrada passava a ser alimentada pelas chamadas "linhas alimentadoras", são responsáveis pela coleta de usuários originários das áreas habitacionais, mediante uso do bilhete único (OLIVEIRA, 2003). Este sistema pode ser visualizado na Figura 2.

Em 2007 inicia a passagem de integração temporal em que o passageiro pode utilizar o mesmo bilhete em outras linhas no intervalo de até 60 minutos. A partir desse mesmo ano o sistema de pagamento do serviço pelos usuários já podia ser realizada através do cartão eletrônico (Smart Card). Tal sistema considerado inovador possibilitava aos usuários fazer recargas de créditos ( $\mathrm{n}$ - de passagens) nos terminais de ônibus e também pela internet. Com a instalação desse sistema o tempo de viagem e espera nos pontos de ônibus foram reduzidos, pois o motorista não dispendia atenção aos usuários (AGETRAN, 2016).

No ano de 2011, o uso do cartão eletrônico (Smart Card) passou a ser exclusivo, dispensando o pagamento em dinheiro. Os usuários poderiam adquirir seus cartões denominados 


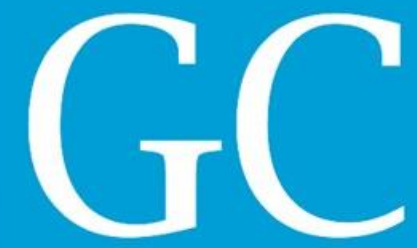

Revista Nacional de

personalizados (recarregáveis) nos terminais ou pela internet, recebendo o mesmo em sua residência ou adquirir de forma unitária (pré-pago). A exclusividade do uso do cartão visa dar aos usuários segurança com relação a assaltos, facilidade de embarque e rapidez no tempo das paradas e deslocamento, hoje esse sistema e o transporte coletivo urbano é operado pelo Consórcio Guaicurus em regime de concessão, totalizando 197 linhas e transporta, uma média de 188.611 passageiros/dia, conforme Tabela 1 (AGETRAN, 2018).

\section{Figura 2 - Sistema Integrado do Transporte Coletivo de ônibus}

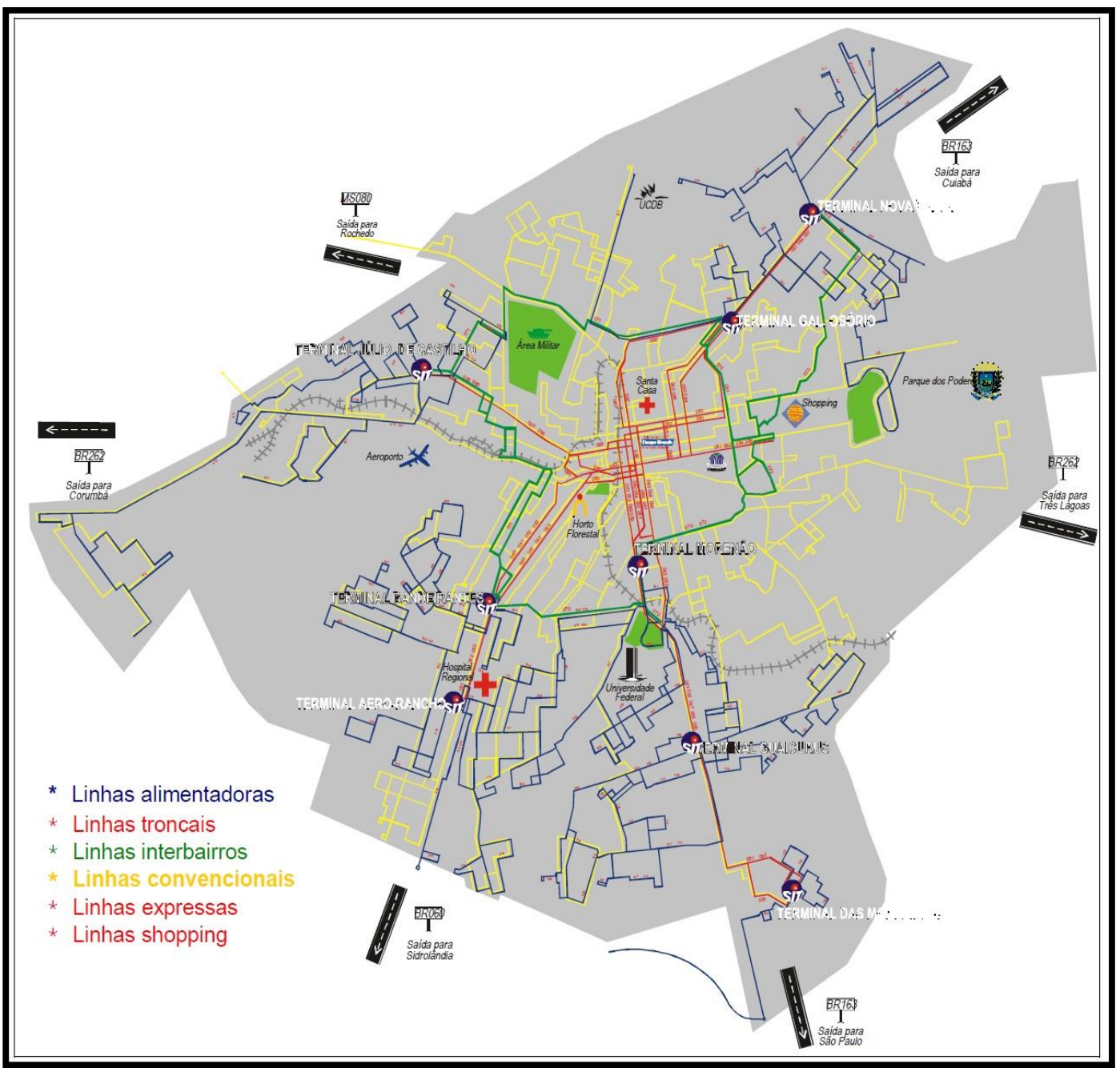

Fonte: TRIVELATTO, 2003. 


\section{Revista Nacional de}

Tabela 1 - Linhas de ônibus existentes em Campo Grande - 2008-2017

\begin{tabular}{|c|c|c|c|c|c|c|c|c|c|c|}
\hline \multirow{2}{*}{ Tipo } & \multicolumn{10}{|c|}{ Quantidade de Linhas } \\
\hline & 2008 & 2009 & 2010 & 2011 & 2012 & 2013 & 2014 & 2015 & 2016 & 2017 \\
\hline Convencional - total & 56 & 53 & 56 & 65 & 64 & 62 & 63 & 62 & 61 & 61 \\
\hline Não integradas & 39 & 36 & 39 & 48 & 47 & 45 & 46 & 45 & 44 & 44 \\
\hline Noturno & 9 & 9 & 9 & 8 & 8 & 8 & 8 & 8 & 8 & 8 \\
\hline Turno & 7 & 7 & 7 & 8 & 8 & 8 & 8 & 8 & 8 & 8 \\
\hline Shopping & 1 & 1 & 1 & 1 & 1 & 1 & 1 & 1 & 1 & 1 \\
\hline Alimentadora (azul) & 74 & 78 & 81 & 81 & 82 & 87 & 87 & 88 & 96 & 98 \\
\hline Interbairro & 6 & 6 & 7 & 7 & 7 & 8 & 8 & 8 & 7 & 7 \\
\hline Troncal (vermelha) - total & 14 & 15 & 15 & 17 & 17 & 17 & 17 & 17 & 17 & 17 \\
\hline Terminal/centro/terminal & 1 & 1 & 1 & 1 & 1 & 1 & 1 & 1 & 1 & 1 \\
\hline Bairro/centro/bairro & 0 & 1 & 1 & 1 & 1 & 1 & 1 & 1 & 1 & 1 \\
\hline Expresso & 4 & 4 & 4 & 4 & 4 & 4 & 4 & 4 & 4 & 4 \\
\hline Terminal/terminal & 4 & 4 & 4 & 4 & 4 & 4 & 4 & 4 & 4 & 4 \\
\hline Shopping & 5 & 5 & 5 & 7 & 7 & 7 & 7 & 7 & 7 & 7 \\
\hline Executivo (micro-ônibus) & 10 & 10 & 10 & 12 & 12 & 12 & 12 & 12 & 12 & 12 \\
\hline Distrital & 1 & 1 & 1 & 1 & 1 & 1 & 1 & 2 & 2 & 2 \\
\hline Total & 161 & 163 & 170 & 183 & 183 & 187 & 188 & 189 & 195 & 197 \\
\hline
\end{tabular}

Fonte: AGETRAN, 2018

Para fim de atender a Política Nacional de Mobilidade Urbana (PNMU), instituída em abril de 2012 pela Lei Federal n. 12.587, Campo Grande preocupou-se em com os requisitos da lei e revisa Plano Diretor em 2009 sendo aprovado pelo prefeito em 2015, porém em revisão na câmara de vereadores. Dentre as principais propostas da nova legislação estão: o estabelecimento de padrões de emissão de poluentes a gestão democrática e o controle social do planejamento e da avaliação da política de mobilidade; uma nova gestão sobre as tarifas de transporte e a integração de políticas de desenvolvimento urbano; a priorização dos modos não motorizados e do transporte público coletivo a priorização dos modos não motorizados e do transporte público coletivo.

\section{CAMPO GRANDE E SEU SISTEMA CICLOVIÁRIO}

No ano de 2009, o município contratou a empresa LOGITRANS, para elaborar um estudo sobre a revisão do Plano Diretor do Município, que visou atender os requisitos do Estatuto da Cidade - Lei Federal no 10.257/2001. A malha cicloviária existente em Campo Grande pode ser observada na Figura 2 e a proposta desenvolvida neste estudo pode ser visualizada na Figura 4.

Como pode ser observado na Figura 3, o diagnóstico levantado por este estudo é que em Campo Grande já existem algumas ciclovias implementadas, porém sem interligação entre elas, e poucas que fazem a ligação a área central da cidade, destino preferencial da maioria das pessoas que se deslocam na cidade. Campo Grande soma 86 quilômetros de vias destinadas ao tráfego de bicicletas (BASÍLIO; SOUZA, 2014).

O estudo para a complementação da rede, de forma a atender às diversas regiões da cidade vislumbra a ampliação das ciclovias existentes de forma a permitir os deslocamentos de bicicleta em todo o perímetro urbano, segundo trabalho realizado pela LOGITRANS (2009). 


\section{Revista Nacional de}

Observa-se que, mesmo no projeto proposto pela empresa, não é prevista a chegada de ciclovias até o quadrilátero central da cidade. Pressupõe-se que a integração entre os modos ônibus-bicicleta pode suprir necessidade de ciclovias no centro da cidade (Figura 3).

Observa-se que a bicicleta não tem seu potencial aproveitado na maior parte das cidades brasileiras, mesmo apresentando um meio eficiente de transporte urbano não motorizado e com um baixo custo de manutenção quando comparado com os automóveis e motocicletas. Em Campo Grande esse potencial não explorado pode ser explicado pela pequena quantidade de ciclovias implantadas, atualmente com $86 \mathrm{Km}$. Quando comparado a quilometragem cicloviária de Campo Grande com demais cidade de porte aproximado, percebemos a defasagem: Curitiba-PR (204 km), Rio Branco-AC (107 km), Goiânia-GO (104km), FlorianópolisSC $(104 \mathrm{~km})(\mathrm{G1}, 2018)$. Outra explicativa para o uso reduzido de bicicletas em Campo Grande pode ser a inexistência de via exclusiva para bicicletas efetivando a ligação com a região central, principal destino dos deslocamentos urbanos (LOGITRANS, 2009).

Figura 3 - Mapa da estrutura cicloviária de Campo Grande

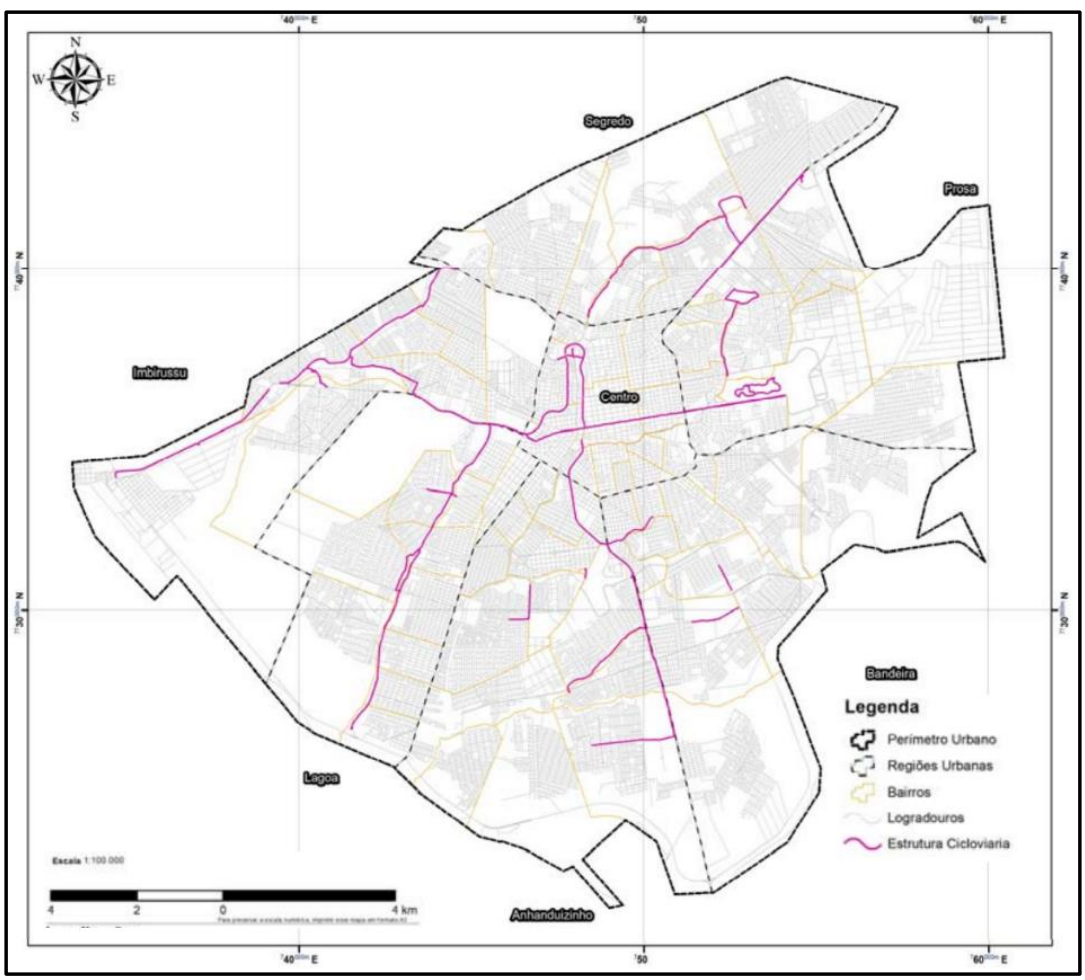

Fonte: PLANURB, 2018 


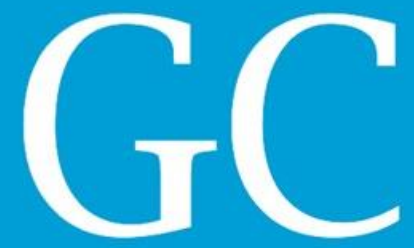

Revista Nacional de

Figura 4 - Mapa do sistema cicloviário proposto em Campo Grande-MS

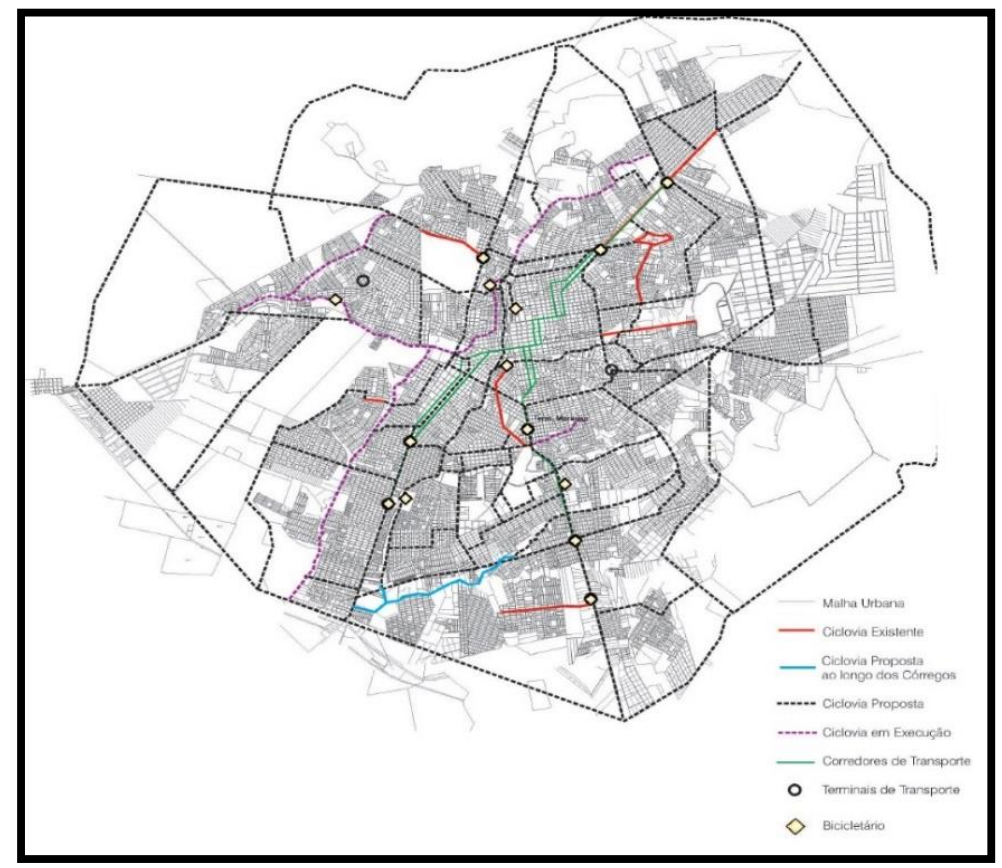

Fonte: LOGITRANS, 2009. (sem escala)

\section{RESTRIÇÃO DE VEÍCULOS PRIVADOS NA ÁREA CENTRAL DE CAMPO GRANDE E ESTIMULO AO USO DA BICICLLETA}

O centro urbano de Campo Grande é predominantemente comercial e de prestação de serviço e, portanto, o fluxo de trabalhadores que partem dos diferentes bairros para o Centro da cidade é grande. Pesquisa realizada com ciclistas da capital apontou que o principal uso da bicicleta é para se deslocar para o trabalho, 72,5\%, pressupondo que um percentual se desloque para o centro (TRANSPORTE ATIVO, 2018). Ainda sobre a pesquisa, quando questionado sobre qual motivo poderia aumentar o uso com mais frequência da bicicleta, $40,5 \%$ responderam que a infraestrutura cicloviária poderia ser melhorada.

Em 2010 a prefeitura discutiu amplamente com a população e também com comerciantes da área central de Campo Grande, a revitalização do centro urbano, que foi aprovada e transformada na lei municipal complementar n. 161, de 20 de julho de 2010 (PLANURB, 2012).

Como resultado da pesquisa e planejamento pela Prefeitura Municipal, o Programa Reviva Campo Grande (CAMPO GRANDE, 2018) é um conjunto de intervenções e obras destinadas a promover a dinamização da economia e qualificação dos espaços públicos da região central da cidade que envolve vários setores públicos para garantir eficiência do transporte coletivo, mobilidade urbana, acessibilidade e fortalecimento dos instrumentos de planejamento e gestão urbana da Prefeitura Municipal (Figura 5). 


\section{Revista Nacional de}

Uma das intervenções da revitalização do centro urbano de Campo Grande é diminuir a circulação de veículos particulares e o de transporte público nas vias que estão passando por esse processo, com o propósito de oferecer um maior espaço para circulação de pedestres e meios não motorizados, como a bicicleta.

Como observado na pesquisa destacada, um fator inibidor para o maior uso das bicicletas em Campo Grande é a pouca estrutura ofertada, principalmente para os maiores fluxos da cidade. Vias compartilhadas com bicicletas devem propiciar conectividade a destinos importantes, como escola, trabalho ou centros comerciais, áreas de recreação e transporte coletivo. Com o presente projeto de revitalização da área central, a aplicabilidade desses novos conceitos e boas práticas podem pressupor um maior uso da bicicleta.

Figura 5 - Programa Reviva Campo Grande. (a) Área de atuação do programa. (b) Interseção da rua 14 de Julho, onde se observa a implantação de bicicletários e alargamento das calçadas nos cruzamentos viários

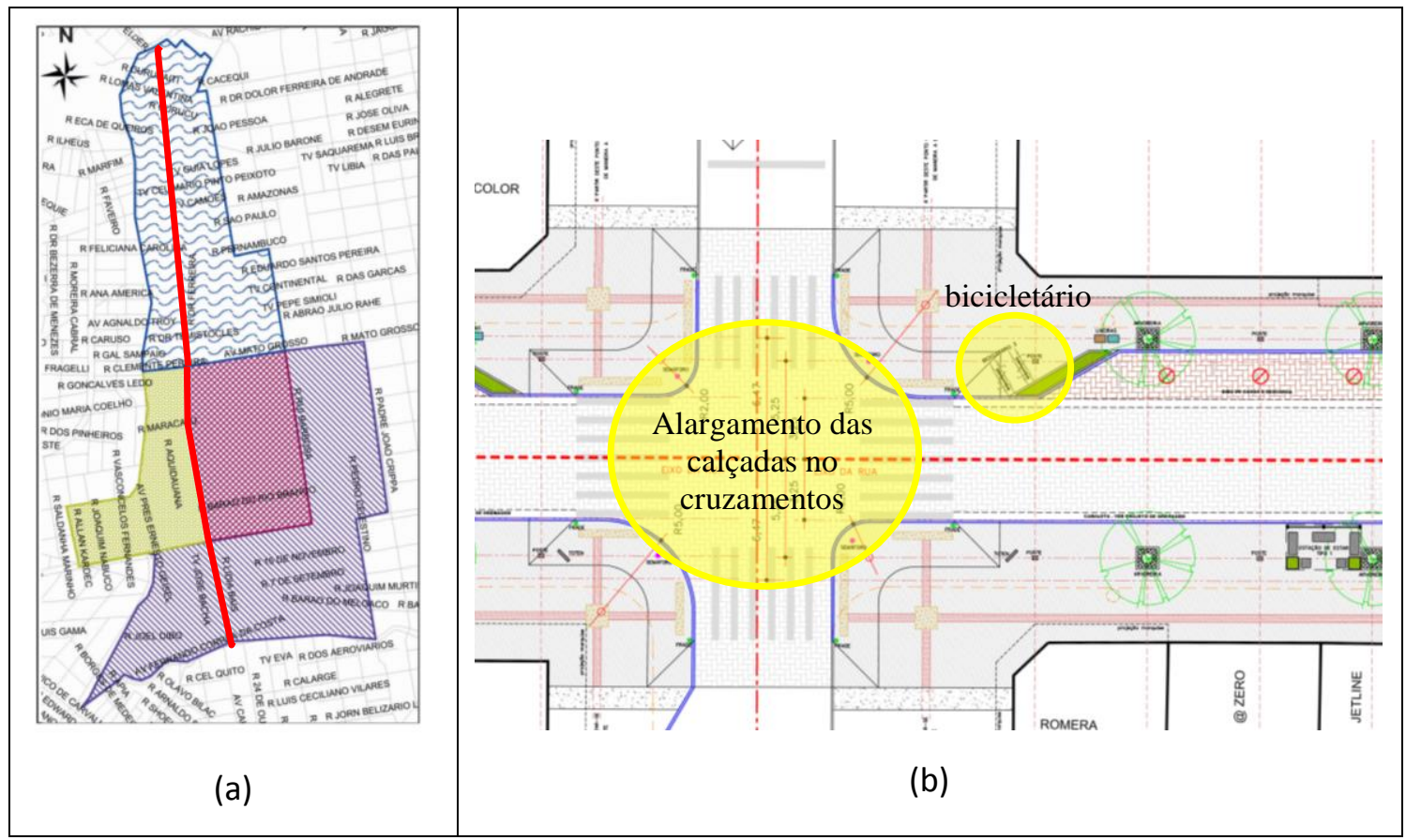

\section{CONSIDERAÇÕES FINAIS}

A busca por alternativas de transportes menos poluentes e impactantes no transporte, bem como desestimular o uso do veículo particular de transportes, faz com que a integração entre os diferentes modos de transportes, como ônibus e bicicleta, devam ter tratamento preferencial, em detrimento de intervenções específicas de expansão da infraestrutura existente (CARVALHO, 2005). 
Tomando como base o planejamento apresentado por programas em Campo Grande, é possível perceber a intenção de estimular modos não motorizados na região central da cidade. Conforme já exemplificado na figura 5, existe a proposta de instalação de bicicletários em locais estratégicos no centro da cidade e próximos aos corredores de transporte público, estabelecendo assim uma integração de modais, tanto dos usuários de bicicleta, ônibus e veículos particulares. Podemos entender que as práticas adotadas como a revisão do Plano Diretor, Plano Diretor de Mobilidade Urbana e as propostas de revitalização da área central, visam portanto, estimular a mobilidade urbana sustentável através do transporte ativo.

\section{REFERÊNCIAS BIBLIOGRÁFICAS}

AGETRAN. Sistema Integrado de Transportes. Disponível em: <http://agetran.ms.gov.br/agetran/sistema-viário>. Acesso em: 5 de mai. 2016.

- PERFIL SOCIOECONÔMICO 25ạ EDIÇÃO REVISTA 2018. Disponível em: http://agetran.ms.gov.br/agetran/transporte-coletivo>. Acesso em: 15 de out. 2018.

BASÍLIO, F. A.; SOUZA, A. O. Infraestrutura de Transporte Coletivo e Mobilidade Urbana em Campo Grande (MS): Análise dos Programas "Pró-Transportes" e PAC2 “Mobilidade Grandes Cidades". 8 ENEPE UFGD, 50 EPEX UEMS. 2014. Disponível em: <http://eventos.ufgd.edu.br/enepex/anais/arquivos/125.pdf>. Acesso em: 27 mar. 2018.

BRASIL. MINISTÉRIO DAS CIDADES. PlanMob: construindo a cidade sustentável - Caderno de Referência para Elaboração de Plano de Mobilidade Urbana. Brasília: Ministério das Cidades, 2015. Disponível em: < http://www.cidades.gov.br/images/stories/ArquivosSE/planmob.pdf>. Acesso em: 01 jun. 2018.

LEI № 12.587, DE 3 DE JANEIRO DE 2012. Política Nacional de Mobilidade Urbana. 2012. Disponível em: <http://www.planalto.gov.br/ccivil_03/_ato2011-2014/2012/lei/l12587.htm>. Acesso em: 01 jun. 2018.

. LEI № 13.406, DE 26 DE DEZEMBRO DE 2016. Estender o prazo exigido para a elaboração do Plano de Mobilidade Urbana e para sua compatibilização com o plano diretor municipal. Disponível em: <http://legis.senado.leg.br/legislacao/ListaTextoSigen.action?norma=602631\&id=14374834\&idBinario=15656022\& mime=application/rtf>. Acesso em: 01 jun. 2018.

CAMPO GRANDE, PLANURB. Perfil socioeconômico 25ạ edição revista 2018. Disponível em: < http://www.campogrande.ms.gov.br/planurb/downloads/perfil-socioeconomico-25a-edicao-revista-2018/>. Acesso em: 15 out. 2018.

PLANURB. Cartilha Reviva Centro, 2012. Disponível em: <http://www.capital.ms.gov.br/centro/>. Acesso em: 15 out. 2018.

PLANURB. Reviva Campo Grande, 2017. Disponível em: <http://www.campogrande.ms.gov.br/reviva/oprograma/>. Acesso em: 15 out. 2018. 
CAMPOGRANDENEWS. Comissão Especial entrega relatório final do Plano Diretor de Campo Grande. Disponível em: <http://www.capitalnews.com.br/politica/comissao-especial-entrega-relatorio-final-do-plano-diretor-decampo-grande/322390>. Acesso em: 15 out. 2018.

CARVALHO, A.C.W., 2005, Desenho Universal, Acessibilidade e Integração Modal - Estudo exploratório no transporte coletivo no Rio de Janeiro, Dissertação de Mestrado em Engenharia de Transporte, Universidade Federal do Rio de Janeiro, RJ.

CUNHA, J. M. P. Dinâmica migratória e o processo de ocupação do Centro-Oeste brasileiro: o caso de Mato Grosso. R. bras. Est. Pop., São Paulo, v. 23, n. 1, p. 87-107, jan./jun. 2006.

GEIPOT, Manual de planejamento cicloviário. - 3. ed., rev. e amp. - Brasília: GEIPOT, 2001.

G1. Malha cicloviária das capitais cresce $133 \%$ em 4 anos e já passa de 3 mil quilômetros, 28 ago. 2018. Disponível em: <https:/g1.globo.com/economia/noticia/2018/08/28/malha-cicloviaria-das-capitais-cresce-133-em-4-anos-eja-passa-de-3-mil-quilometros.ghtml>. Acesso em: 15 out. 2018.

IBGE, Censo Demográfico 2010. Características da população e dos domicílios: resultados do universo. Rio de Janeiro: $\quad$ IBGE, 2011. Acompanha 1 CD-ROM. Disponível em: <http://www.ibge.gov.br/home/estatistica/populacao/censo2010/caracteristicas_da_populacao/resultados_do_un iverso.pdf>. Acesso em: 28 mai. 2018.

Estimativas da população residente para os municípios e para as unidades da federação brasileiros com data de referência em 1o de julho de 2017. Disponível em: <https://www.ibge.gov.br/estatisticasnovoportal/sociais/populacao/9103 estimativas-de-populacao.html?=\&t=downloads>. Acesso em: 15 mai. 2018.

IPEA - INSTITUTO DE PESQUISA ECONÔMICA APLICADA. Mobilidade urbana sustentável: conceitos, tendências e reflexões. Brasília: Ipea, 2016.

LOGITRANS, Plano Diretor de Transporte e Mobilidade Urbana (PDTMU) de Campo Grande-MS, 2009. Disponível em: <http://www.campogrande.ms.gov.br/planurb/downloads/plano-diretor-de transporte-e-mobilidade-urbana pdtmu-de-campo-grande-decreto-n-12-681/>. Acesso em: 06 mar. 2018.

NTU - ASSOCIAÇÃO NACIONAL DE EMPRESAS DE TRANSPORTES URBANOS. Boas práticas para a nova mobilidade urbana. Brasília: NTU, $2012 . \quad$ Disponível em: <http://www.fetranspordocs.com.br/downloads/26BoasPraticasNovaMobilidade.pdf>. Acesso em: 03 abr. 2018.

OLIVEIRA, J.G.R de. A importância do sistema de transporte coletivo para o desenvolvimento do município de Campo Grande/ MS. Dissertação (Mestrado em Desenvolvimento Local), UCDB, 2003.

SAGARIS, L., ARORA, A. Evaluating how cycle-bus integration could contribute to "sustainable" transport. 2016. Research in Transportation Economics, 2016, vol. 59, issue C, 218-227

SANTOS, MILTON. A Urbanização Brasileira. São Paulo: Hucitec, 1993.

TRANSPORTE ATIVO. Perfil do ciclista, 2018. Disponível em: <http://transporteativo.org.br/ta/?p=11575>. Acesso em: 15 out. 2018. 


\section{Revista Nacional de}

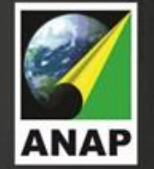

Gerenciamento de Cidades

National Journal of Cities Management

TRIVELLATO, F.A.A. Os impactos ambientais do transporte urbano em Campo Grande: estudo de caso da rua Rui Barbosa. Campo Grande: UNIDERP, 2002. (Dissertação de mestrado em Meio Ambiente). 